\title{
Laboratory Evaluation of Insecticidal Activity of Phytolacca Dodecandra L.'Herit Leaves Extracts Against Bedbug, (Heteroptera: Cimicidae)
}

\author{
Deniel Kebede ${ }^{1}$, Seblework Mekonnen ${ }^{1}$, Argaw Ambelu ${ }^{1}$, Kaliyaperumal \\ Karunamoorthi ${ }^{1,2, \dagger}$
}

\author{
${ }^{1}$ Department of Environmental Health Sciences and Technology, College of Public Health \& Medical \\ Sciences, Jimma University, Jimma, Ethiopia \\ ${ }^{2}$ Department of Environmental Health Sciences, Faculty of Public Health \& Tropical Medicine, Jazan \\ University, Kingdom of Saudi Arabia \\ karunamoorthi@gmail.com
}

\begin{abstract}
Bedbugs are hematophagous insects that have plagued humans for over centuries. In recent decades bedbug infestation raising dramatically worldwide because of the emergence of insecticide resistance, notably pyrethroids. Therefore, the aim of this investigation was to evaluate the insecticidal properties of Ethiopian indigenous plant Endod [vernacular name (local native language, Amharic); Phytolacca dodecandra L'Hérit] leaf extracts against bedbugs, under the laboratory conditions. Insecticidal bio-assay was performed against bedbugs. Both fresh (crude) and dried (acetone) leaves extracts of endod were impregnated to filter paper disc [(Whatman No. 1, 90mm); cut to $2.27 \mathrm{~cm}^{2}(1.7 \mathrm{~cm}$ diam)] at various concentrations. Bedbugs were exposed for 2 $h$, subsequently transferred to an untreated environment and monitored for mortality at 24, 48 and $78 h$ intervals. Extracts of P. dodecantra exhibited various degrees of insecticidal activity against bedbugs. However, acetone extract has demonstrated quite remarkable insecticidal effects against bedbugs in terms of the higher mortality rate than the crude extract. The $L C_{50}, L C{ }_{90}$ and $L C_{99}$ values of the crude extract were at $24 \mathrm{~h}(3.986$, 17.373 and $57.680 \mathrm{mg} / \mathrm{l}), 48 \mathrm{~h}(3.127,14.576$, and $51.126 \mathrm{mg} / \mathrm{l})$, and $72 \mathrm{~h}(2.960,14.202$ and $50.91 \mathrm{mg} / \mathrm{l})$ post exposure. Whereas $L C_{50}, L C_{90}$ and $L C_{99}$ values of the acetone extract were at $24 \mathrm{~h}(3.127,14.576$ and 51.126 $\mathrm{mg} / \mathrm{l}), 48 \mathrm{~h}$ (2.790, 13.730, and $50.327 \mathrm{mg} / \mathrm{l})$ and $72 \mathrm{~h}$ (2.586, 10.464 and $32.703 \mathrm{mg} / \mathrm{l})$ post treatment. The findings are clearly exhibited that the percent of mortality directly proportional to concentration as well as the period of exposure dependent. Green insecticides are often preferable because of their low mammalian and non-target toxicity. The findings clearly established the bio-potency of Endod as a safe alternative bedbug control agent. Nevertheless, further scientific studies are warranted to identify responsible bio-active molecules, their mode of action, safety to the human, non-target organism and environment. Besides, adequate measures have to be made by bringing various pertinent stakeholders in order to formulate and commercialize the endodbased insecticide to effectively combat bedbugs in the future.
\end{abstract}

Keywords: Bedbugs, Phytolacca dodecandra, Endod, Ethiopia

\section{INTRODUCTION}

Bedbugs are obligatory hematophagous ectoparasites that have been one of the most common and annoying pests in human history [1-3]. In recent decades, bedbug infestation has increased dramatically across the United States, Canada, Europe, Australia, Asia as well as in many African countries and beyond [4]. It has been linked to increased international travel, changes in pest management practices (including increased regulatory constraints removing certain chemical insecticides from operational use)[5], and the wide scale spread of insecticide resistance[6-8].

In Africa, tropical bedbug, (Cimex hemipterus L.) distributed throughout warm zones [1], whereas temperate one, C. lectularius L. is common in the rest of the Africa [9]. Bedbugs are wingless, reddish-brown, dorso-ventrally flattened tiny $(5-7 \mathrm{~mm})$ insects. Their size, nocturnal and cryptic behavior as well as the potential for developing insecticide resistance makes them difficult to detect, control and eradicate [10]. Bedbug infestation and associated pruritic bites cause a variety of emotional and psychological impacts [11]. It also causes a range of clinical symptoms vary from asymptomatic to severe cutaneous, allergic and systemic reactions. Nevertheless, thus far they are not scientifically authenticated as the insect vector of diseases to human. 
Irrespective of the socioeconomic status, all sections of the society are vulnerable of being bitten. However, bedbug infestation is widespread in the poverty-stricken settings, especially in low- and middle-income countries (LMICs), as it is inextricably intertwined with poverty [12]. It has been estimated that nearly eighty percent of the Ethiopians are living in the isolated remote villages and they are predominantly living in the substandard housing, which impose a severe risk to the infestation. Nevertheless, it is one of the most neglected public health care issues or concerns owing to the massive disease burden of the major killer diseases viz. Tuberculosis, HIV/AIDS and Malaria in this country [12]. Chemical interventions are often recommended [13] but the existing conventional insecticides are becoming feckless $[14,15]$ because of resistance and it is a potential threat to the global public health [16].

Accordingly, currently bedbugs have proven to be a challenging pest to contain or eradicate and it becomes the subject of significant research and public health concern than ever before [12]. In Ethiopia, the indiscriminate use of chemical insecticide imposes a severe health hazard to human and environmental hazard because of poor insecticidal management practices [17-18]. It insists to explore the development of next generation cost-effective vector control tools in terms of new classes of plant-based insecticide with novel mode of action to effectively curb the bedbug infestation in the future.

From these perspectives, the present communication becomes more substantial and pertinent. The plant kingdom is a potential warehouse to develop and deploy several eco-user-friendly repellents/insecticides because of their unique bio-active molecules. Ethiopia remains regarded as a potential repository of traditional insecticidal plants attributable to its varied climatic and topographic features [19-22]. Over decades Ethiopian and other African people have been using the berries of endod as a laundry detergent for washing clothes [23]. It is a proven botanical pesticide to control Schistosomiasis transmitting snails. Because of its molluscicidal (direct poisoning of snails) properties it can be used as an alternative insecticidal agent against mosquitoes and other insects[24], particularly bedbugs.

To the best of our knowledge and understanding to date, several studies have been reported on the chemistry, toxicity, and epidemiology of triterpenoid saponins (Lemmatoxins), larvicidal, pupicidal, antifungal, antiprotozoan, spermicidal, and molluscicidal properties of endod. Nevertheless, this is the first study was conducted to assess on the insecticidal activity of endod against bedbugs, which is one of the potential public health and medical hazards in this country. This communication could pave the way to develop an effective, cheap, safe and sustainable bedbug control interventions by formulating a risk-reduced green (ecological) insecticide as well as to minimize the heavy reliance of conventional insecticides and resistance for the control of bedbugs in the future.

\section{MATERIALS AND METHODS}

\subsection{Plant Selections and Identification}

In this study, a plant with known toxicity properties was selected from secondary data i.e. some reports in the literature or some bio-ethnological knowledge by the farmers, fisherman and local residents. Plant species of endod showing toxicity properties was chosen. Since ancient time the peoples have used this plant as a phytotherapeutic agent for numerous ailments [23]. In Ethiopia, high mortality of snails was noticed in natural water bodies, where people using endod berries as a detergent and subsequently, comprehensive investigations made and proved its molluscicidal activities[25]. The collected voucher specimen has been identified, pressed, numbered, dried, and deposited in the Jimma University Regional Herbarium, Ethiopia.

\subsection{Taxonomy of Phytolacca Dodecandra L.'Herit}

Kingdom: Plantae

Division: Angiosperms

Class: Eudicots

Order: Caryophyllales

Family: Phytolaccaceae

Genus: Phytolacca

Species: dodecandra 


\subsection{Preparation of Crude Extract from the Fresh Leaves}

The fresh leaves of endod were collected from the outskirts of Jimma town, Oromiya Region, Ethiopia, and brought to the Environmental Health Sciences and Technology and Environmental Biology laboratories of Jimma University. The leaves were shredded into pieces subsequently $200 \mathrm{~g}$ of the shredded leaves were taken and crushed with distilled water to obtain paste by using a mortal pistil grinder. Then, the paste was dissolved in $400 \mathrm{ml}$ distilled water. The mixed solution was kept for $24 \mathrm{~h}$, then the solution was filtered with cheese cloth and filter paper [26]. The filtered fresh leaves (crude) extract was stored in the refrigerator at $4^{\circ} \mathrm{C}$ for later use. Then $10 \mathrm{ml}$ of the extract was serially diluted to achieve different test concentrations viz., $6.97 \mathrm{mg} / 1,13.95 \mathrm{mg} / 1,27.5 \mathrm{mg} / \mathrm{l}$, and $55 \mathrm{mg} / \mathrm{l}$, and $111 \mathrm{mg} / \mathrm{l}$.

\subsection{Preparation of Acetone Extract from the Dried Leaves}

Endod leaves were shade dried at room temperature $\left(29 \pm 1^{\circ} \mathrm{C}\right)$ for twenty days and the dried leaves were powdered by using electrical blender. The $100 \mathrm{~g}$ endod powder was kept in six conical flasks with $1000 \mathrm{ml}$ capacity and $600 \mathrm{ml}$ of acetone (solvent) was poured into each flask. Mouths of flasks were covered with aluminum foil and placed in a water bath for $72 \mathrm{~h}$ for continuous agitation for thorough mixing and complete elucidation of bio-active molecules to dissolve in the solvent. Then the extract was filtered by using Whatman filter paper ( 540 hardened ash less circles, $110 \mathrm{~mm}$ thickness CAT No. 1540 110). The solvent (acetone) from the crude extract was removed by using a rotary vacuum evaporator with the water bath temperature of $50^{\circ} \mathrm{C}$. Finally, the residue of dried leaves was collected in a vial (also known as a phial or flacon) and stored in refrigerator at $4^{0} \mathrm{C}$ for subsequent usage. One $\mathrm{g}$ of the extract residue was measured and the stock solution was prepared by adding one $\mathrm{ml}$ of acetone and $99 \mathrm{ml}$ of distilled water. Then five $\mathrm{ml}$ of the of the stock solution was taken and serially diluted in $95 \mathrm{ml}$ of distilled water to acquire different concentrations viz., $0.003 \mathrm{mg} / \mathrm{l}$, $0.062 \mathrm{mg} / 1,1.25 \mathrm{mg} / \mathrm{l}, 25 \mathrm{mg} / \mathrm{l}$ and $500 \mathrm{mg} / \mathrm{l}$.

\subsection{Collection and Preparation of Bed Bugs}

A total of 726 adult bedbugs of mixed sex were collected from the Jimma University student's dormitory by the well-trained insect collectors under the close supervision of a professional medical entomologist by using the forceps and torch light. The investigators asked the students to launder their infested items. The collected bedbugs were placed in the petri dishes. Good laboratory handling procedures were adopted and practiced for the collection, preservation and transportation of bedbugs. Subsequently the collected bedbugs were identified up to genus level (Cimex spp.) by using the standard bedbugs identification key. Consequently, these bedbugs were subjected to the standard bioassay test by exposing the unfed (no blood meal for 12d) and uniform sized adult bed bugs of mixed sex and of random collection from the colony (which are collected from the student's dormitory) and maintained in the laboratory for the experimentation purpose.

\subsection{Determination of the Toxicity of the Fresh and Dried Leaf Extracts}

Initially filter paper disc [(Whatman No. $1,90 \mathrm{~mm})$; cut to $2.27 \mathrm{~cm}^{2}(1.7 \mathrm{~cm}$ diam)] was placed in eighteen petri dishes and then the discs were impregnated with $2 \mathrm{ml}$ crude extract at different concentrations viz., $6.97 \mathrm{mg} / 1,13.95 \mathrm{mg} / 1,27.5 \mathrm{mg} / 1$, and $55 \mathrm{mg} / \mathrm{l}$, and $111 \mathrm{mg} / \mathrm{l}$, allowed to dry completely. Whereas the acetone extract the discs were impregnated with $2 \mathrm{ml}$ of $0.003 \mathrm{mg} / \mathrm{l}$, $0.062 \mathrm{mg} / \mathrm{l}, 1.25 \mathrm{mg} / \mathrm{l}, 25 \mathrm{mg} / \mathrm{l}$ and $500 \mathrm{mg} / \mathrm{l}$ concentrations. Three replicates were set up by placing twenty bedbugs (1:1 sex ratio) per petri dish, which was then covered and exposed for $2 \mathrm{~h}$. The control groups were set up by treating the disc with distilled water and acetone alone to compare with their respective test groups. After $2 \mathrm{~h}$ the exposed bedbugs were transferred to an unsprayed environment (another petri dish without filter paper disc) and monitored. Mortality was assessed by gently touching each individual with a fine paint brush at 24,48 and $72 \mathrm{~h}$ of the post treatment interval. The moribund and dead bedbugs in each concentration were combined in quadruplicate and expressed as percentage mortalities. Every bioassay was carried out under standard laboratory conditions (temperature $\sim 25 \pm 2^{\circ} \mathrm{C}$; humidity $\sim 80 \% \pm 10 \% \mathrm{RH}$; 14-h light and 10-h dark cycle), and replicated three times with bedbugs from different batches.

\subsection{Data Managements and Analysis}

It was important in order to obtain no less than three mortality counts of between $10 \%$ and $90 \%$. The average bedbug mortality data were subjected to probit analysis[27] for calculating $\mathrm{LC}_{50}, \mathrm{LC}_{90}$ and other statistics at $95 \%$ confidence limits of upper confidence limit and lower confidence limit, and 
chi-square values were calculated using the SPSS12.0 (Statistical Package for Social Sciences: Chicago, IL, USA) software. Control and treatment, mortality was compared with a chi-square analysis. A significant chi-square value indicates that the population was susceptible. Results with $p<$ 0.05 were considered to be statistically significant. In cases where the control mortality was between $5-20 \%$, the observed percent mortality $(\% \mathrm{M})$ was corrected by Abbott's formula[28]:

Observed mortality $(\%)$ - Control mortality $(\%)$

Corrected mortality $=$

$$
100 \text { - Control mortality (\%) }
$$

\section{RESUlts}

\subsection{Toxicity of the Fresh Leaf Extract}

Leaves extracts of $P$. dodecantra exhibited various degrees of insecticidal activity against bedbugs under the laboratory conditions.. The results are presented in Tables 1, and 2, as well as Figures 1, 2 and 3. The figures 1,2, and 3 are clearly suggesting that both fresh (crude) and dried leaves (acetone) extracts of $P$. dodecantra have excellent insecticidal properties against bedbugs, causing rapid mortality following short-term (2h) exposure to spray residues. However, acetone extract has shown quite remarkable insecticidal activity than the crude extract. The bioassay findings in terms of the estimated $\mathrm{LC}_{50}, \mathrm{LC}_{90}$ and $\mathrm{LC}_{99}$ values of the crude extract at $24 \mathrm{~h}(3.986,17.373$ and $57.680 \mathrm{mg} / \mathrm{l}) 48$ $\mathrm{h}(3.127,14.576$, and $51.126 \mathrm{mg} / \mathrm{l})$ and $72 \mathrm{~h}(2.960,14.202$ and $50.91 \mathrm{mg} / \mathrm{l})$ post exposure (Table 1 , Figure 1 and 3). Whereas the estimated $\mathrm{LC}_{50}, \mathrm{LC}_{90}$ and $\mathrm{LC}_{99}$ values of the acetone extract at $24 \mathrm{~h}$ $(3.127,14.576$ and $51.126 \mathrm{mg} / \mathrm{l}) 48 \mathrm{~h}(2.790,13.730$, and $50.327 \mathrm{mg} / \mathrm{l})$ and $72 \mathrm{~h}(2.586,10.464$ and $32.703 \mathrm{mg} / \mathrm{l}$ ) post exposure (Table 2, Figure 2 and 3). These lethal concentration values are clearly exhibited that the percent of mortality directly proportional to the dose and time of exposure dependent. The obtained results apparently established the potentiality of endod as a bedbug's control agent.

Table1. The estimated $L C_{50}, L C_{90}$ and $L C_{99}$ values and confidence limits of the P. dodecandra crude extract at 24,48 and 72 h post exposure intervals.

\begin{tabular}{|c|c|c|c|c|c|c|}
\hline \multirow[b]{2}{*}{ S. No. } & \multirow{2}{*}{$\begin{array}{l}\text { Post Exposure } \\
\text { Period (h) } \\
\end{array}$} & \multirow{2}{*}{$\begin{array}{l}\text { Values } \\
(\mathrm{mg} / \mathrm{l})\end{array}$} & \multirow{2}{*}{$\begin{array}{l}\text { Exposure } \\
\text { Concentrations }\end{array}$} & \multicolumn{2}{|c|}{ 95\% Confidence Limits } & \multirow[b]{2}{*}{$P$ - values } \\
\hline & & & & Lower & Upper & \\
\hline \multirow{3}{*}{1.} & \multirow{3}{*}{24} & $\mathrm{LC}_{50}$ & 03.986 & 02.491 & 05.563 & \\
\hline & & $\mathrm{LC}_{90}$ & 17.373 & 01.385 & 39.187 & $0.000 *$ \\
\hline & & $\mathrm{LC}_{99}$ & 57.680 & 28.564 & 264.720 & \\
\hline \multirow{3}{*}{2.} & \multirow{3}{*}{48} & $\mathrm{LC}_{50}$ & 03.127 & 01.715 & 04.5 & \\
\hline & & $\mathrm{LC}_{90}$ & 14.576 & 09.509 & 34.3 & $0.001 *$ \\
\hline & & $\mathrm{LC}_{99}$ & 51.126 & 24.632 & 279.5 & \\
\hline \multirow{3}{*}{3.} & \multirow{3}{*}{72} & $\mathrm{LC}_{50}$ & 02.960 & 01.553 & 04.308 & \\
\hline & & $\mathrm{LC}_{99}$ & 14.202 & 09.224 & 34.032 & $0.001 *$ \\
\hline & & $\mathrm{LC}_{99}$ & 50.910 & 24.241 & 298.323 & \\
\hline
\end{tabular}

Note: *Statistically significant at $p<0.001$ level

Table2. The estimated $\mathrm{LC}_{50}, \mathrm{LC}_{90}$ and $\mathrm{LC}_{99}$ values and confidence limits of the $P$. dodecandra acetone extract at 24,48 and $72 \mathrm{~h}$ post exposure intervals.

\begin{tabular}{|c|c|c|c|c|c|c|}
\hline \multirow[b]{2}{*}{ S. No. } & \multirow{2}{*}{$\begin{array}{l}\text { Post Exposure } \\
\text { Period }(h)\end{array}$} & \multirow{2}{*}{$\begin{array}{l}\text { Values } \\
(\mathrm{mg} / \mathrm{l})\end{array}$} & \multirow{2}{*}{$\begin{array}{l}\text { Exposure } \\
\text { Concentrations }\end{array}$} & \multicolumn{2}{|c|}{ 95\% Confidence Limits } & \multirow[b]{2}{*}{$P$ - values } \\
\hline & & & & Lower & Upper & \\
\hline \multirow{3}{*}{1.} & \multirow{3}{*}{24} & $\mathrm{LC}_{50}$ & 03.127 & 01.715 & 04.498 & \\
\hline & & $\mathrm{LC}_{90}$ & 14.576 & 09.509 & 34.248 & $0.001 *$ \\
\hline & & $\mathrm{LC}_{99}$ & 51.126 & 24.632 & 279.466 & \\
\hline \multirow{3}{*}{2.} & \multirow{3}{*}{48} & $\mathrm{LC}_{50}$ & 02.790 & 01.393 & 04.110 & \\
\hline & & $\mathrm{LC}_{90}$ & 13.730 & 08.888 & 33.477 & $0.002 *$ \\
\hline & & $\mathrm{LC}_{99}$ & 50.327 & 23.653 & 315.048 & \\
\hline \multirow{3}{*}{3.} & \multirow{3}{*}{72} & $\mathrm{LC}_{50}$ & 02.586 & 01.357 & 03.703 & \\
\hline & & $\mathrm{LC}_{90}$ & 10.464 & 07.097 & 22.624 & $0.005^{*}$ \\
\hline & & $\mathrm{LC}_{99}$ & 32.703 & 16.916 & 159.858 & \\
\hline
\end{tabular}

Note: *Statistically significant at $\mathrm{p}<0.001$ level 
Laboratory Evaluation of Insecticidal activity of Phytolacca dodecandra L.'Herit leaves extracts against Bedbug, (Heteroptera: Cimicidae)

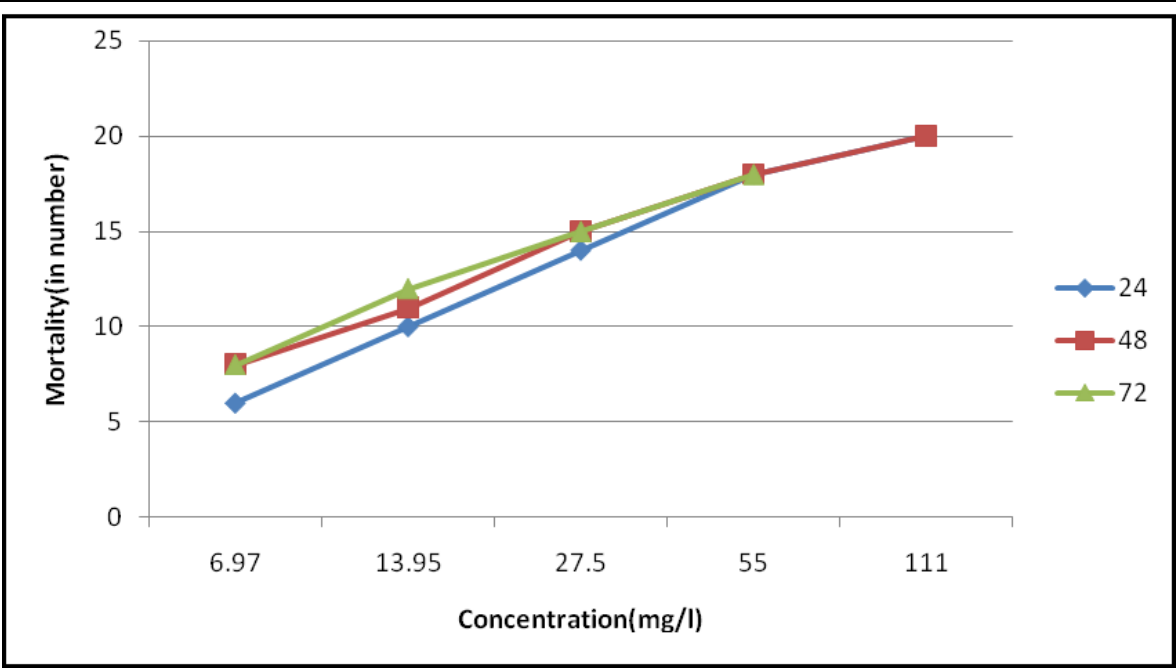

Fig1. The insecticidal activity of $P$. dodecandra the crude extract after 24, 48 and 72 h of exposure at different concentrations.

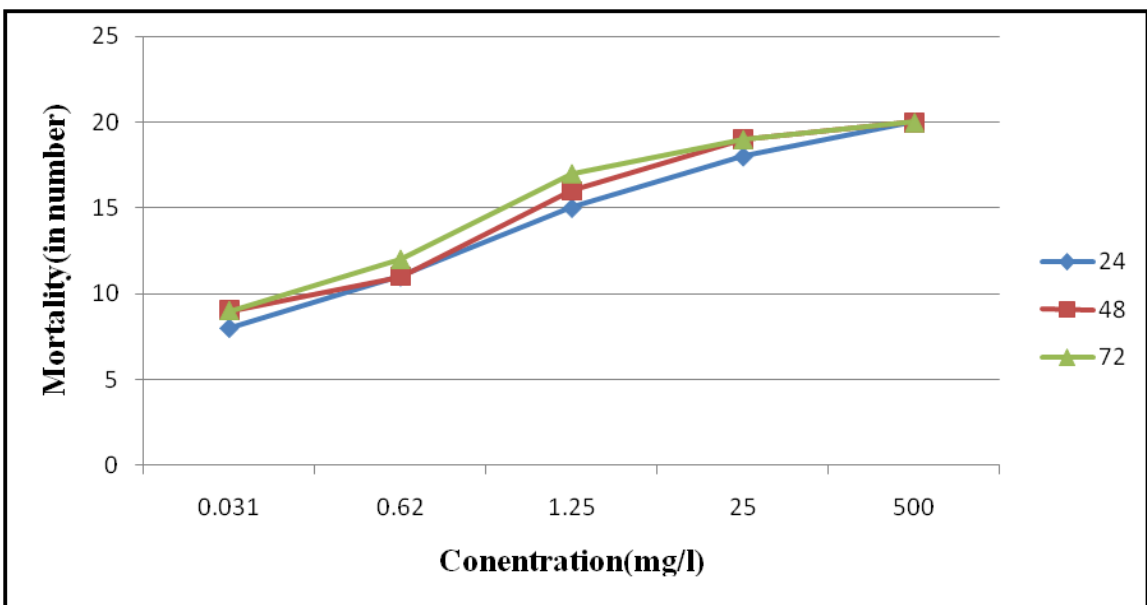

Fig2. The insecticidal activity of $P$. dodecandra the acetone extract after 24, 48 and $72 h$ of exposure at different concentrations.

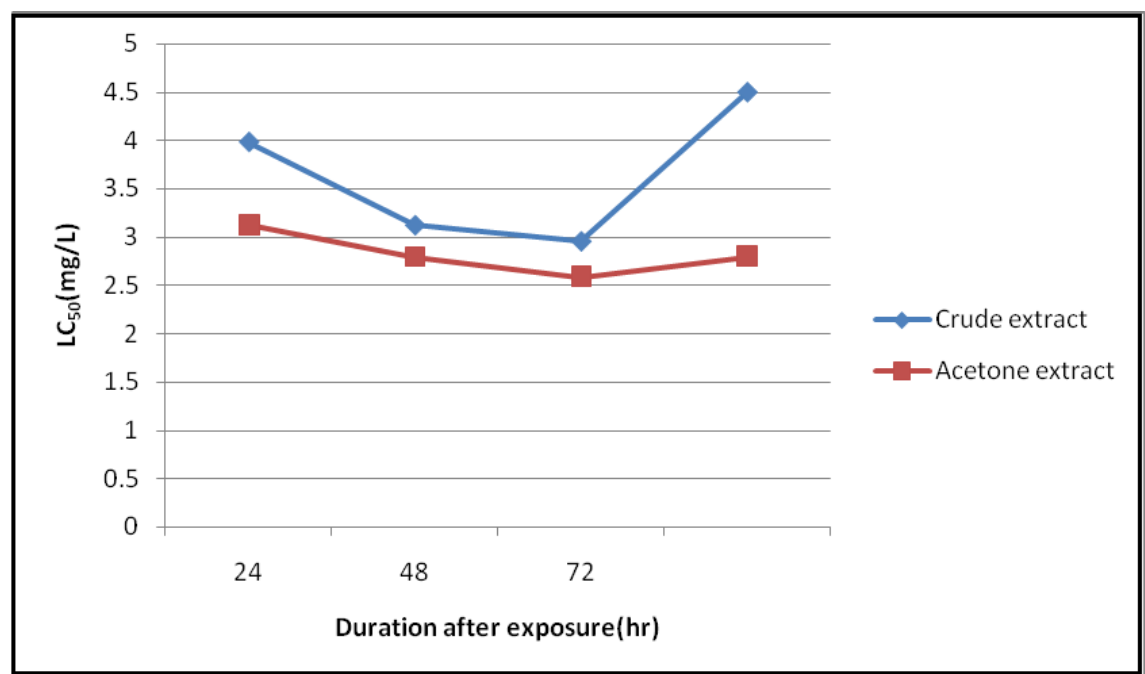

Fig3. $L C_{50}$ value of $P$. dodecandra crude and acetone extracts after 24,48 and 72 h of post treatment.

\section{Discussion}

Since time immemorial, humans have been using hundreds of thousands of plants as phytotherapeutic agents, Nutraceuticals and insecticidal to lead a healthier and a contentment life[29]. Indeed, prior to the advent of synthetic insecticides humankind solemnly relies on plants for his domestic, agriculture 
and public health insect control needs. Usage of plants for the control of bed bugs is not a new phenomenon and it is a age-old practice. South all imported Nonpareil liquor from Jamaica to control bedbugs [1,3] and it might have been prepared with Quassia wood (an insecticidal tree), but the formula has been lost. In North America, people made beds from Sassafras wood to repel bedbugs in the mid of the 1700s [3]. In 1800s the extract of dried pyrethrum flowers (Persian Insect Powder), was extensively used in Europe and Asia, and in the United States [3]. In these historical perspectives, this study attempted to authenticate the insecticidal properties of a known plant, endod against bedbugs, where it is one of the most neglected public health issues in this country.

The result evidently demonstrated that the crude extract was potentially lethal to bedbugs in all the tested concentrations. The $\mathrm{LC}_{50}, \mathrm{LC}_{90}$ and $\mathrm{LC}_{99}$ values were $3.98 \mathrm{mg} / \mathrm{l}, 17.37 \mathrm{mg} / \mathrm{ml}$ and $57.6 \mathrm{mg} / \mathrm{l}$, respectively at $24 \mathrm{~h}$ post exposures. However, there were significant levels of higher mortality rate observed when the bedbugs are exposed for 48 and $72 \mathrm{~h}$. It is mainly due to the extension of the exposure period (Table 1, Figure 1 and 3). The discovery of the molluscicidal properties of endod led to the isolation, purification, and followed by elucidation of the chemical structure of the toxic principle $[30,31]$ were considered to be a one of the pioneer research works on the Ethiopian research history. Subsequently, endod butanol extract was evaluated for its mosquitocidal properties against second and third instar larvae of Aedes aegypti, Culex pipiens and Anophelese quadrimaculatus. It found that endod is considerably more toxic than rotenone and about 100 times as active as a commercial saponin preparation[32]. Debella et al. (2007)[33] also proved the mosquito larvicidal properties of endod against Ae. africanus, Ae. aegypti and Cx. quinquefasciatus.

Table 2 validate that the acetone extract was more noxious to bedbugs than the crude extract. The $\mathrm{LC}_{50}, \mathrm{LC}_{90}$ and $\mathrm{LC}_{99}$ of acetone extract were $3.12 \mathrm{mg} / 1,14.57 \mathrm{mg} / \mathrm{l}$ and $51.12 \mathrm{mg} / 1$, respectively at the 24 $\mathrm{h}$ post exposure. Similarly like crude extact the acetone extract also demonstrated a higher mortality rate when the exposure time extends to 48 and $72 \mathrm{~h}$ (Table 2, Figure 2 and 3). The results are quite comparable to a recent study conducted in Ethiopia reported that the different solvent extract of $P$. dodecandra against larvae of Cx quinquefasciatus. It found that the petroleum ether, acetone and benzene extracts were highly toxic when compared with methanol and crude extracts[34].

Similarly, the present study findings suggest that the extracts of endod has long residual effects against bedbugs, which resulted in higher mortality when the exposure period extends to more than 24 $\mathrm{h}$ (Figure 1,2 and 3). The results are consistent with an Ethiopian study, which reported that when the exposure time and concentrations are increased a higher rate of mortality also observed[34]. These led to other investigations which demonstrated the susceptibility of larvae of the notorious black fly (Simulium spp.), the vector of onchococerciasis or river blindness[35] and larvae of the domestic house fly, Musca domestica. Further development and formulation of endod as an insecticide for village level use could have significant public health impact[36] in this country in the near future.

The above cited studies substantiate that endod has a significant level of broad spectrum insecticidal properties for the control of public health pests like beddbugs. Accordingly, crude and acetone extracts caused considerable mortality within the $24 \mathrm{~h}$ of post exposure resulted lowest $\mathrm{LC}_{50}$ values (Table 1 and 2). The findings are concurrent with an earlier study, which indicates that the concentration of endod required to kill mosquitoes is lesser than that which kills snails and fish[32]. Interestingly, over centuries berries of endod have been used for washing clothes in streams and lakeshores in Ethiopia and the rest of Africa, without any apparent adverse effect[36]. Furthermore, in Ethiopia and elsewhere in Africa, high concentrations of the endod leaves, roots, or berries are taken orally as phytotherapeutic agents for various ailments, such as for purging intestinal parasites and for abortion[37]. These reports advocate that the extracts of endod can be used as a potential bedbug's control agent by considering their user-and-eco-friendly merits. It could further minimize the exclusive reliance of chemical insecticides and their associated health risk and environmental hazard.

Irrespective of the types of extracts, both crude and acetone have contributed higher percent of mortality (100\%) against bedbugs at all tested higher concentrations (Figure 1, 2 and 3). It could be possibly explained that the berries of Phytolacca type 44 species contained $25 \%$ by weight of saponin[31], which is the active principle for molluscidal properties. Thus, the higher rate of mortality may be ascribable to the presence of saponin and other secondary metabolites. Endod is well known for their omnipotent properties. The berries of endod synthesize various triterpenoid saponins, which possess potent and useful biological properties including detergent, molluscicidal [30, 38, 39], spermicidal[37], insecticidal[32], and fungicidal[24] properties. 
Nevertheless, Endod is scientifically authenticated as a potential molluscicidal agent, which kills the intermediate host snails that harbor schistosome parasites that cause schistosomiasis or bilharzias [40]. One of the most important criteria for widespread use of any insecticides is its safety to humans, animals using the treated bodies of water and local flora and fauna. Toxicological studies also exhibited that the endod fruit extracts do not have mutagenic or carcinogenic properties [41, 42]. Furthermore, a recent report suggests that the saponin of $P$. dodecandra was stable for only two days, then begin to dwindle in the following days ultimately bio-degraded ( $t 1 / 2=15.8 \mathrm{~h}$ ), within ten to twenty-one days[43].

These reports indicate that the extract of $P$. dodecandra can be useful as a safe and low-cost possible alternative to costlier synthetic insecticides in the bedbug control attributable to its bio-degradable nature. However, further research is warranted to explore the efficacy and safety of Endod-based insecticide towards the human beings, livestocks and environment to formulate and market it as a potential insecticidal agent to control insects of public health importance, especially mosquitoes and bedbugs in the future. Interestingly, endod is one of the endemic plants and widely distributed across Ethiopia and the rest of the Africa. It provides an ideal opportunity for us to generate the income among the rural poor by cultivation as well as to develop and deploy risk reduced (ecological) insecticides from the endod plants. We hope it could contribute to substantial alleviation of poverty in this nation in the future.

\section{CONClusion}

Plants contain numerous primary and secondary metabolites (bio-active molecules) in order to fend for themselves from their natural enemies [herbivores (predominantly insects)] and pathogens. Green pesticides are often easily accessible, affordable, user and eco-friendly in nature, and they become more attractive alternative insecticides to resource-limited settings [44]. The present study results apparently exhibit that the candidate plant endod has remarkable noxious or insecticidal activity against bedbugs. Since, bedbugs have developed resistance against most of the conventional insecticides, particularly pyrethroids, which is considered to be one of the profound factors in the recent resurgence of bedbugs in the widespread settings. In this context endod could play a pivotal role as a potent bedbug control agent in the near future. Withal, this communication warrants further investigations to elucidate the responsible bio-active principles, mode of action and safety. Besides, adequate measures have to be made by bringing a multidisciplinary act, with a range of pertinent stakeholders in order to formulate and commercialize the endod-based insecticide in the future.

\section{ACKNOWLEDGEMENT}

We are also grateful to the Mr.Abiy Andemo for his technical assistance, without his contribution, this study would have been impossible. Our last but not least heartfelt thanks go to our colleagues from the School of Environmental Health Science, Faculty of Public Health, Jimma University, Jimma, Ethiopia, for their kind support and cooperation.

\section{FUNDING}

This work was supported by Research and Publication Division of Jimma University, Ethiopia.

\section{COMPETING INTERESTS}

None declared.

\section{REFERENCES}

[1] Usinger RL. Monograph of Cimicidae (Hemiptera, Heteroptera), vol. 7, Thomas Say Foundation Series, Entomological Society of America: College Park, MD, 1966;585.

[2] Cooper R. Chapter 8 - Ectoparasites, part three: bed bugs and kissing bugs. In: A. Mallis, S. Hedges, D. Moreland (Editors), Mallis Handbook of Pest Control, The Mallis Handbook Company, Richfield, Ohio, USA, 2011;587-632.

[3] Potter MF. The history of bed bug management - with lessons from the past. Am Entomol 2011; 57: $14-25$.

[4] Harlan H. Bed bugs 101: The basics of Cimex lectularius Am Entomol 2006; 105-106.

[5] Boase C. Bed bugs: research and resurgence. In: Takken, W., Knolls, B.G.J., (Eds.), Emerging Pests and Vector-Borne Diseases in Europe, vol. 1. Wageningen Academic Publishers; 2007. 
[6] Moore R, Miller D. Laboratory evaluations of insecticide product efficacy from control of Cimex lectularius. J Econ Entomol 2006; 99: 2080-2086.

[7] Romero A, Potter MF, Potter DA, Haynes KF. Insecticide resistance in the bed bug: a factor in the pest's resurgence? J Med Entomol 2007; 44(2): 175-178.

[8] Seong KM, Lee DY, Yoon KS, Kwo, DH, Kim HC, Klein TA, Clark JM, Lee SH. Establishment of quantitative sequencing and filter contact vial bioassay for monitoring pyrethroid resistance in the common bed bug Cimex lectularius. J Med Entomol 2010; 47: 592-599.

[9] Newberry K, Jansen E, Thibaud G. The occurrence of the bed bugs Cimex hemipterus and Cimex lectularius in northern natal and kwazulu, South $\quad$ Africa. Trans Royal Soc Trop Med Hyg 1978; 81: 431-433.

[10] Wang C, Saltzmann K, Chin E, Bennett GW, Gibb T. Characteristics of Cimex lectularius (Hemiptera: Cimicidae), infestation and dispersal in a high-rise apartment building. $J$ Econ Entomol 2010; 103(1): 172-7.

[11] Goddard J, de Shazo R. Psychological Effects of Bed Bug Attacks (Cimex lectularius L.). Am J Med 2012; 125(1): 101-103. doi:10.1016/j.amjmed.2011.08.010.

[12] Karunamoorthi K, Buzuna B, Ambelu A. Risk Indicators associated with the Prevalence of Bedbug Infestation and Containment Practices in the Ethiopian Resource Constrained Setting. Pasitol Res. 2015. (Under Review).

[13] Doggett S. A code of practice for the control of bed bug infestations in Australia 2007. Available at: http://medent.usyd.edu.au/bedbug/bedbug $\square$ cop.htm [accessed on $15^{\text {th }}$ February 2014].

[14] Wang C, Abou El-Nour M, Bennett GW. Controlling bed bugs in apartments: a case study. Pest Control Technol 2007; 35(11): 64, 66, 68, 70.

[15] Potter MF. The business of bed bugs. Pest Manag Professional 2008; 76(1): 24-25, 28-32, 34, $36-40$

[16] Karunamoorthi K, Sabesan S. Insecticide Resistance in Insect Vectors of Disease with Special Reference to Mosquitoes: A Potential Threat to Global Public Health. Health Scope 2013; 2(1): 4-18. DOI:10.5812/jhs.9840.

[17] Karunamoorthi K, Mohammed M, Wassie F. Knowledge and Practices of Farmers With Reference to Pesticide Management: Implications on Human Health. Arch Environ Occup Health 2012; 67(2): 109-116.

[18] Karunamoorthi K, Mohammed A, Jemal Z. Peasant association member's knowledge, attitudes, and practices towards safe use of pesticide management. Am J Ind Med 2011; 54(12): 965-970. DOI: 10.1002/ajim.21008.

[19] Karunamoorthi K, Ilango K, Endale A. Ethnobotanical survey of knowledge and usage custom of traditional insect/mosquito repellent plants among the Ethiopian Oromo ethnic group. $J$ Ethnopharmacol 2009a; 125(2): 224-229.

[20] Karunamoorthi K, Mulelam A, Wassie F. Assessment of knowledge and usage custom of traditional insect/mosquito repellent plants in Addis Zemen Town, South Gonder, North Western Ethiopia. J Ethnopharmacol 2009b; 121(1): 49-53.

[21] Karunamoorthi K, Husen E. Knowledge and self-reported practice of the local inhabitants on traditional insect repellent plants in Western Hararghe Zone, Ethiopia. J Ethnopharmacol 2012; 141(1): 212-219. doi: 10.1016/j.jep.2012.02.022.

[22] Karunamoorthi K, Teklu H. Insect Repellent Plants Traditional Usage Practices in the Ethiopian Malaria Epidemic-Prone Setting: An Ethnobotanical Survey. J Ethnobiol Ethnomed 2014; 10:22. doi:10.1186/1746-4269-10-22.

[23] Karunamoorthi K, Bishaw D, Mulat T. Laboratory evaluation of Ethiopian local plant Phytolacca dodecandra extract for its toxicity effectiveness against aquatic macro invertebrates. Eur Rev Med Pharmacol Sci

[24] in Ethiopia. Proceedings of a preparatory workshop held in Nazareth: Addis Ababa University Press, 1994;62-66.

[25] Lemma A. Laboratory and field evaluation of the molluscicidal property of Phytolacca dodecandra. Bull World Health Organ 1970; 42: 597-617. 
[26] Jembere B. Evaluation of the toxicity potential of Milletia ferrginea (Hoechst) Baker against Sitophillus zeamais (Motsch.). Int J Pest Management 2002; 48(1): 29-32.

[27] Finney DJ. Probit Analysis. Cambridge University Press: Cambridge, UK; 1971.

[28] Abbott WS. A method for computing the effectiveness of the insecticide. J Econ Entomol 1925; 18: 265-267.

[29] Karunamoorthi K, Jegajeevanram K, Vijayalakshmi J, Embialle $M$. Traditional Medicinal Plants: A Source of Phytotherapeutic Modality in the Resource-Constrained Health Care Settings. J Evid Based Complement Alternat Med 2013; 18: 67-74.

[30] Lemma A. A preliminary report on the molluscicidal property of endod (Phytolacca dodecandra). Ethiopian Med J 1965; 3: 187-190.

[31] Lemma A, Brody G, Newell GW, Parkhurst RM, Skinner WA. Studies on the molluscicidal properties of endod (Phytolacca dodecandra). I. Increased potency with butanol extraction. $J$ Parasitol 1971; 58(1): 104-7.

[32] Spielman A, Lemma A. Endod extract, plant derived molluscicide: Toxic for mosquitoes. Am J Trop Med Hyg 1973; 22: 802-804.

[33] Debella A, Taye A, Abebe D, Mudi K, Melaku D, Taye G. Screening of some Ethiopian medicinal plants for mosquito larvicidal effects and phytochemical constituents. Pharmacol Online 2007; 33: 231-243.

[34] Nurie M, Shiferaw M, Muche T, Mamaye T, Tigab T, Nagappan R. Evaluation of multi potential Bioactive Endod, Phytolacca Dodecandra (L'Herit) Berries Extracts against Immature Filarial Vector Culex quinquefasciatus say (Dipter: Culicidae). Res J Environ Earth Sci 2012; 4: 697-703.

[35] Karunamoorthi K, Kassa E, Endale A. Knowledge and beliefs about causes, transmission, prevention and control of onchocerciasis among the rural inhabitants in an endemic area of Ethiopia. Int Health 2010; 2(1): 59-64. DOI:10.1016/j.inhe.2009.11.002.

[36] Institute of Biodiversity Conservation (IBC). Genetic Resources Transfer and Regulation Directorate, IBC.The prospectus of Phytolacca dodecandra (Endod) for commercialization and industrial utilization 2012. Available at: http://www.ibc.gov.et/gm-access/gm [accessed on 14th February 2014].

[37] Stolzenberg SJ, Parkhurst RM. Blastocidal and contraceptive actions by an extract and compounds from endod (Phytolacca dodecandra). Contraception 1976; 14: 39-51.

[38] Parkhurst RM, Thomas DW, Skinner WA, Cary LW. Molluscicidal saponins of Phytolacca dodecandra: Lemmatoxin. Can J Chem 1974; 52: 702-705.

[39] Lemma A, Wolde-Yohannes L, Praleigh PC, Klerks PL, Lee HH. Endod is lethal to Zebra Mussels and inhibit their attachment. J Shellfish Res 1991; 10: 361-365.

[40] Semagn K, Stedje B, Bjornstad A. Patterns of phenotypic variation in endod (Phytolacca dodecandra) from Ethiopia. Afr J Biotechnol 2004; 3(1): 32-39.

[41] Lambert JDH, Temmink JHM, Marquis J, Parkhurst RM, Lugt CB, Schoonen AJM, Holtze K, Warner JE, Dixon G, Wolde-Yohannes L, Desavigny D. Endod: Safety evaluation of a plant molluscicide. Regul Toxicol Pharmacol1991; 14(2): 189-201.

[42] Lemma A, Yau P. Studies on the molluscicidal properties of endod (Phytolacca dodecandra). II. Toxicity of various molluscicides to fish and snails. Ethiop Med J 1974; 12: 109-114.

[43] Molgard P, Chihaka A, Lemmich E, Furu P, Windberg C, Ingerslev F, Halling Sorrensen B. Biodegradablity of the molluscicidal saponins of Phytolacca dodecandra. Regul Toxicol Pharmacol 2000; 32: 248-255.

[44] Karunamoorthi, K. Medicinal and Aromatic Plants: A Major Source of Green Pesticides/Riskreduced Pesticides. J Med Aromat Plants 2013; 1: e137. doi: 10.4172/2167-0412.1000e137. 